\title{
Antibacterial Effect of Eucalyptus Essential Oil
}

\author{
Nashwa Fawzy Abd El Moez Azzam* \\ Department of Microbiology, High Institute of Public Health, Alexandria University, \\ Egypt
}

Article Type: Article

Article Citation: Nashwa Fawzy Abd El Moez Azzam. Antibacterial effect of Eucalyptus essential oil. Indian Journal of Science and Technology. 2020; 13(07),799-804.D0l:10.17485/ijst/2020/ v013i07/149824

Received date: January 4, 2020

Accepted date: January 25, 2020

*Author for correspondence: Nashwa Fawzy Abd El Moez Azzam - nashwazam@yahoo.com 9 Department of Microbiology, High Institute of Public Health, Alexandria University, Egypt

\begin{abstract}
Background: To determine minimum inhibitory concentration (MIC) of the Eucalyptus essential oil (EEO) and different antibiotics on Staphylococcus aureus ATCC 29213 and Pseudomonas aeruginosa ATCC 27853, and on twenty bacterial isolates from wound swabs (10 S. aureus and 10 P. aeruginosa). In addition, to evaluate the antibacterial effect of combinations of EEO with selected antibiotics. Methods: Skin infection swabs were cultured; all bacterial isolates were identified according to conventional methods. Ten-gram positive isolates (S. aureus), and ten gram negative isolates ( $P$. aeruginosa) were used to determine MIC of some antibiotics and EEO by broth microdilution methods. Checkerboard method was used to calculate fractional inhibitory concentration indexes. Findings: EEO exhibited a synergistic activity against S. aureus ATCC 29213 but only gave additive effect against $P$. aeruginosa ATCC 27853. Outcome of oil/vancomycin combination found to be synergistic in all tested clinical S. aureus isolates from infected wound swabs. While $80 \%$ of clinical $P$. aeruginosa isolates showed additive outcome of EEO/ ceftazidime combination, and only $20 \%$ of them gave indifference outcome. Application: Dermatological applications of EEOs have been growing with great popularity worldwide. It can be used as ointments to treat various dermatological conditions such as abscesses, athlete's foot, dermatitis, bacterial infections, blisters, boils, burns, cuts, and wounds
\end{abstract}

Keywords: Bacterial Drug Resistance; Essential Oils; Infected Wounds; Natural Compounds, Synergism.

\section{Introduction}

New antimicrobial compounds are needed to fight through the battle between humans and disease-causing pathogens, especially with the appearance of multidrug resistance [1]. Nature is a precious reservoir of natural antibacterial compounds extracted from marine animals, microorganisms, and plants [2].

Essential oils (EOs) are an odorous and volatile compound produced from only $10 \%$ of the plant kingdom [3]. The antibacterial activity of EOs depends on their chemical 
composition [4]. Different antibacterial mechanisms such as disruption of the cell wall, and penetration of cell membrane had been proposed [5]. Difference in bacterial cell structure caused gram-negative bacteria to be more resistant to EOs than gram-positive bacteria. A new concept to face bacterial resistance is to combine conventional antimicrobial agents and EOs to reduce the minimum effective dose of antibiotics and thus minimize their adverse effects [6]. Oil of Eucalyptus plant (EEO) is one of the most promising essential oils to treat wound infections [7].

This research aims to discover the antibacterial synergystic effect of EEO in Egypt, as medicinal plants differ in their effect according to ecophysiological properties of plants grown in different geographical areas [8].

\section{Material and Methods}

\subsection{Study Area}

This study was carried during two-month period from beginning of September to end of October 2019. Infected wound swabs were obtained from different private hospitals in Alexandria.

\subsection{Laboratory Investigation}

\subsubsection{Volatile Oil Preparation}

Commercial EEO from Imtenan health shop (Imtenan) was dissolved to a final concentration of $0.001 \%$ Tween 80 to enhance oil solubility and diffusion [9].

\subsubsection{Isolation and Identification of the Clinical Isolates}

Skin infection swabs were inoculated on blood and MacConkey agarplates and incubated aerobically at $37{ }^{\circ} \mathrm{C}$ for $24 \mathrm{~h}$. All bacterial isolates will be identified according to conventional methods [10].

\subsubsection{Determination of Minimal Inhibitory Concentration of the Eucalyptus Essential Oil and Some Antibiotics on Isolated Bacteria}

The minimal inhibitory concentrations (MICs) were determined by broth microdilution methods. MIC was determined as the lowest concentration without bacterial growth [11].

\subsubsection{Determination of Effect of Combination of Eucalyptus essential oil with Some Antibiotics}

Checkerboard method was used to calculate Fractional inhibitory concentration indexes (FICIs): FICI = FIC A (MIC of substance an in combination/MIC of substance an alone) + FIC B (MIC of substance B in combination/MIC of substance B alone). It was considered synergistic when the FICI value is $\leq 0.5$, additive when it was 0.5 to $\leq 1$, indifferent when it was 1-4.0, and antagonistic when it was $>4$ [12]. 


\subsubsection{Statistical Analysis}

Data were tabulated analyzed using statistical software SPSS version 24 (IBM Corp., Chicago, IL). Descriptive statistics of demographic variables were calculated including frequencies, percentages.

\section{Results}

The FIC and FICI values of the EEO and some antibiotics against Staphylococcus aureus ATCC 29213 and Pseudomonas aeruginosa ATCC 27853 were determined with the broth microdilution method (Table 1).

The oil exhibited a synergistic activity against $S$. aureus but only gave additive effect against $P$. aeruginosa. Determination of FIC of some antibiotics against $S$. aureus and $P$. aeruginosa isolates from infected wound swabs (Table 2). The MIC values of the EEO and vancomycin against ten $S$. aureus isolates from infected wound swabs were determined with broth microdilution method (Table 3). Outcome of oil/vancomycin combination

TABLE 1. Determination of FICl of EEO and some antibiotics on S. aureus ATCC 29213 and P. aeruginosa ATCC 27853

\begin{tabular}{llllcc}
\hline \multirow{2}{*}{$\begin{array}{l}\text { Antimicrobial } \\
\text { substances }\end{array}$} & \multicolumn{2}{c}{$\begin{array}{c}\text { S. aureus } \\
\text { ATCC 29213 }\end{array}$} & & $\begin{array}{c}\text { P. aeruginosa } \\
\text { ATCC 27853 }\end{array}$ & \\
\cline { 2 - 6 } & FIC & FICI & & FIC & FICI \\
\hline EEO & 0.11 & 0.26 & EEO & 0.25 & 0.75 \\
Vancomycin & 0.25 & & Ceftazidime & 0.50 & \\
EEO & 0.25 & 0.37 & EEO & 0.20 & 1 \\
Ampicillin & 0.12 & & Ciprofloxacin & 0.80 & \\
EEO & 0.18 & 0.21 & EEO & 0.25 & 0.96 \\
Ceftriaxone & 0.03 & & Gentamicin & 0.71 & \\
\hline
\end{tabular}

TABLE 2. Determination of FIC of some antibiotics against $\mathrm{S}$. aureus and $\mathrm{P}$. aeruginosa isolates from infected wound swabs

\begin{tabular}{llccccc}
\hline Strains & \multicolumn{3}{c}{ S. aureus isolates } & \multicolumn{3}{c}{ P. aeruginosa isolates } \\
\cline { 2 - 7 } & Vancomycin & Ampicillin & Ceftriaxone & Ceftazidime & Ciprofloxacin & Gentamicin \\
\hline No 1 & 0.125 & 0.13 & 0.17 & 0.002 & 0.80 & 0.75 \\
No 2 & 0.0625 & 0.18 & 0.31 & 1 & 0.75 & 0.90 \\
No 3 & 0.125 & 0.25 & 0.20 & 0.062 & 0.50 & 1.13 \\
No 4 & 0.0625 & 0.12 & 0.29 & 0.002 & 0.80 & 1 \\
No 5 & 0.125 & 0.75 & 0.18 & 0.002 & 0.50 & 0.63 \\
No 6 & 0.125 & 0.13 & 0.28 & 0.002 & 0.71 & 0.38 \\
No 7 & 0.0625 & 0.19 & 0.18 & 0.002 & 0.83 & 0.63 \\
No 8 & 0.125 & 0.20 & 0.13 & 0.002 & 0.96 & 0.50 \\
No 9 & 0.0625 & 0.20 & 0.26 & 0.002 & 0.80 & 0.38 \\
No 10 & 0.125 & 0.16 & 0.12 & 0.002 & 0.50 & 0.38 \\
\hline
\end{tabular}


TABLE 3. Antibacterial effect of EEO and vancomycin combination against $\mathrm{S}$. aureus isolates from infected wound swabs

\begin{tabular}{lllllll}
\hline \multirow{2}{*}{ Strains } & \multirow{2}{*}{ Agents } & \multicolumn{2}{c}{ MIC } & \multicolumn{2}{c}{ FIC } & Outcome \\
\cline { 1 - 3 } S. aureus & & Alone & Combination & FIC & FICI & \\
\cline { 3 - 6 } No 1 & EEO & 0.05 & 0.00625 & 0.125 & 0.25 & Synergistic \\
& Vancomycin & 0.002 & 0.00025 & 0.125 & & \\
No 2 & EEO & 0.05 & 0.01250 & 0.25 & 0.31 & Synergistic \\
& Vancomycin & 0.002 & 0.000125 & 0.0625 & & \\
No 3 & EEO & 0.04 & 0.00624 & 0.156 & 0.28 & Synergistic \\
& Vancomycin & 0.002 & 0.00025 & 0.125 & & \\
No 4 & EEO & 0.05 & 0.01250 & 0.25 & 0.31 & Synergistic \\
& Vancomycin & 0.002 & 0.000125 & 0.0625 & & \\
No 5 & EEO & 0.05 & 0.00625 & 0.125 & 0.25 & Synergistic \\
& Vancomycin & 0.002 & 0.00025 & 0.125 & & \\
No 6 & EEO & 0.05 & 0.00625 & 0.125 & 0.25 & Synergistic \\
& Vancomycin & 0.002 & 0.00025 & 0.125 & & \\
No 7 & EEO & 0.03 & 0.01250 & 0.41 & 0.47 & Synergistic \\
& Vancomycin & 0.002 & 0.000125 & 0.0625 & & \\
No 8 & EEO & 0.04 & 0.00624 & 0.156 & 0.28 & Synergistic \\
& Vancomycin & 0.002 & 0.00025 & 0.125 & & \\
No 9 & EEO & 0.03 & 0.01250 & 0.41 & 0.47 & Synergistic \\
& Vancomycin & 0.002 & 0.000125 & 0.0625 & & \\
No 10 & EEO & 0.05 & 0.00625 & 0.125 & 0.25 & Synergistic \\
& Vancomycin & 0.002 & 0.00025 & 0.125 & & \\
\hline
\end{tabular}

found to be synergistic in all tested clinical $S$. aureus isolates. The MIC values of the EEO and ceftazidime against ten $P$. aeruginosa isolates from infected wound swabs were determined with broth microdilution method (Table 4 ). $80 \%$ of $P$. aeruginosa showed additive outcome of oil/ceftazidime combination, and only $20 \%$ of them gave indifference outcome.

TABLE 4. Antibacterial effect of EEO and ceftazidime combination against P. aeruginosa isolates from infected wound swabs

\begin{tabular}{|c|c|c|c|c|c|c|}
\hline \multirow{2}{*}{$\begin{array}{l}\text { Strains } \\
\text { P. aeruginosa }\end{array}$} & \multirow[t]{2}{*}{ Agents } & \multicolumn{2}{|r|}{ MIC } & \multicolumn{2}{|c|}{ FIC } & \multirow[t]{2}{*}{ Outcome } \\
\hline & & Alone & Combination & FIC & FICI & \\
\hline \multirow[t]{2}{*}{ No 1} & EEO & 0.05 & 0.03 & 0.6 & 0.60 & Additive \\
\hline & Ceftazidime & 0.125 & 0.00025 & 0.002 & & \\
\hline \multirow[t]{2}{*}{ No 2} & EEO & 0.05 & 0.00625 & 0.125 & 1.12 & Indifference \\
\hline & Ceftazidime & 0.0125 & 0.0125 & 1 & & \\
\hline \multirow[t]{2}{*}{ No 3} & EEO & 0.05 & 0.05 & 1 & 1.06 & Indifference \\
\hline & Ceftazidime & 0.002 & 0.000125 & 0.062 & & \\
\hline \multirow[t]{2}{*}{ No 4} & EEO & 0.05 & 0.04 & 0.8 & 0.80 & Additive \\
\hline & Ceftazidime & 0.125 & 0.00025 & 0.002 & & \\
\hline \multirow[t]{2}{*}{ No 5} & EEO & 0.08 & 0.05 & 0.62 & 0.622 & Additive \\
\hline & Ceftazidime & 0.125 & 0.00025 & 0.002 & & \\
\hline \multirow[t]{2}{*}{ No 6} & EEO & 0.05 & 0.03 & 0.6 & 0.602 & Additive \\
\hline & Ceftazidime & 0.125 & 0.00025 & 0.002 & & \\
\hline
\end{tabular}




\begin{tabular}{lllllll}
\hline \multirow{2}{*}{ No 7} & & & & & & \\
& EEO & 0.05 & 0.04 & 0.8 & 0.80 & Additive \\
No 8 & Ceftazidime & 0.125 & 0.00025 & 0.002 & & \\
& EEO & 0.08 & 0.05 & 0.62 & 0.622 & Additive \\
No 9 & Ceftazidime & 0.125 & 0.00025 & 0.002 & & \\
& EEO & 0.07 & 0.04 & 0.57 & 0.57 & Additive \\
No 10 & Ceftazidime & 0.125 & 0.00025 & 0.002 & & \\
& EEO & 0.05 & 0.04 & 0.8 & 0.80 & Additive \\
& Ceftazidime & 0.125 & 0.00025 & 0.002 & & \\
\hline
\end{tabular}

\section{Discussion}

Thick lipopolysaccharide layers of gram-negative bacteria serve as a barrier to entry of several antimicrobial especially those with lipophilic characteristics. In the present study, EEO exhibited a synergistic activity against S. aureus ATCC 29213, and all tested clinically isolated $S$. aureus indicating that the oil has a different mode of action to penicillin. EEO had a synergistic antibacterial activity against gram positive bacteria ( $S$. aureus), while against gram negative bacteria (P.aeruginosa) it was found to be additive or indifference. This agree with the results reported earlier [11], that an inhibitory activity of essential oil was found against all gram-positive bacteria and yeasts but no activity against gram-negative bacteria. Different investigations had discussed the efficacy of essential oils against gram positive and negative bacteria, and showed that gram positive bacteria more susceptible to oils [13-14]. However, in [15], reported different results where EO in combination with antimicrobial drugs considerably reduced the effective doses of the drugs used with $E$. coli isolates despite relatively high MIC values of this EO.

In our study, missing data like the minimum bactericidal concentration were not estimated; more numbers of isolates should be tested to assess the efficacy of EEO and different antibiotics.

\section{Conclusion}

EEO had synergistic antibacterial activity against gram positive bacteria, while against gram negative bacteria it was found to be additive.

\section{References}

1. Wińska K, Mączka W, Łyczko J, Grabarczy M, Czubaszek A, Szumny A. Essential oils as antimicrobial agents-myth or real alternative? Review. Molecules. 2019, 24(11), 2130. https:// doi.org/10.3390/molecules24112130

2. Koehn FE, Carter GT. The evolving role of natural products in drug discovery. Nature Reviews. Drug Discovery. 2005, 4(3), 206-220. DOI:10.1038/nrd1657.

3. Kalemba D, Kunicka A. Antibacterial and antifungal properties of essential oils. Current Medicinal Chemistry. 2003, 10(10), 813-829. 
4. Dorman HJ, Deans SG. Antimicrobial agents from plants: antibacterial activity of plant volatile oils. Journal of Applied Microbiology. 2000, 88(2), 308-316. https://www.ncbi.nlm.nih.gov/ pubmed/10736000

5. Burt S. Essential oils: their antibacterial properties and potential applications in foods - a review. International Journal of Food Microbiology. 2004, 94(3), 223-253. DOI:10.1016/j. ijfoodmicro.2004.03.022.

6. Rosato A, Vitali C, De Laurentis N, Armenise D, Antonietta Milillo M. Antibacterial effect of some essential oilsadministered alone or in combination with Norfloxacin. Phytomedicine:International Journal of Phytotherapy and Phytopharmacology. 2007, 14(11), 727-732. DOI:10.1016/ j.phymed.2007.01.005.

7. Akkol E, Tumen I, Guragac F, Keles H, Reunanen M. Characterization and wound repair potential of essential oil Eucalyptus globulus Labill. In: $9^{\text {th }}$ Annual European Pharma Congress. 2017. DOI: 10.4172/2167-7689-C1-025.

8. Ostad Asiaei E, Moghimipour E, Fakoor MH. Evaluation of antimicrobial activity of Eucalyptus camaldulensis essential oil against the growth of drug-resistant bacteria. Jundishapur Journal of Natural Pharmaceutical Products. 2018, 13(4), e65050. DOI: 10.5812/JJNPP.65050.

9. Aldoghaim FS, Flematti GR, Hammer KA. Antimicrobial activity of several cineole-rich Western Australian Eucalyptus essential oils. Microorganisms. 2018, 6(4). DOI: 10.3390/ microorganisms6040122.

10. Tille P. Bailey \& Scott's diagnostic microbiology. 14th edn. Mosby: United States of America. 2014.

11. Mulyaningsih S, Youns M, El-Readi MZ, Ashour ML, Nibret E, Sporer F, Wink M. Biological activity of the essential oil of Kadsura longipedunculata (Schisandraceae) and its major components. The Journal of Pharmacy and Pharmacology. 2010, 62(8), 1037-1044. DOI:10.1111/j.2042-7158.2010.01119.x.

12. European Committee on Antimicrobial Susceptibility Testing (EUCAST). EUCAST wishes to add one more PK-PD-expert to the committee - are you the expert we are looking for? http:// www.eucast.org/. Date accessed: 2019.

13. Smith-Palmer A. Antimicrobial properties of plant essentialoils and essences against five important food-borne pathogens. Letters ofApplied Microbiology. 1998, 26, 118-122. https:// www.ncbi.nlm.nih.gov/pubmed/9569693

14. Inouye S. Antibacterial activity of essential oils and theirmajor constituents against respiratory tract pathogens by gaseous contact. Journal of Antimicrobial Chemotherapy. 2001, 47(5), 565573. https://www.ncbi.nlm.nih.gov/pubmed/11328766

15. Athanasios Alexopoulos, Athanasios C. Kimbaris, Stavros Plessas, Ioanna Mantzourani, Chrysa Voidarou, Olga Pagonopoulou, Christina Tsigalou, Maria Fournomiti, Christos Bontsidis, Elisavet Stavropoulou, Virginia Papaemmanouil, Eugenia Bezirtzoglou. Expand the author list. Combined action of piperitenone epoxide and antibiotics against clinical isolates of Staphylococcus aureus and Escherichia coli. Frontiers in Microbiology. 2011, 10, 1-10. DOI: 10.3389/fmicb.2019.02607. 